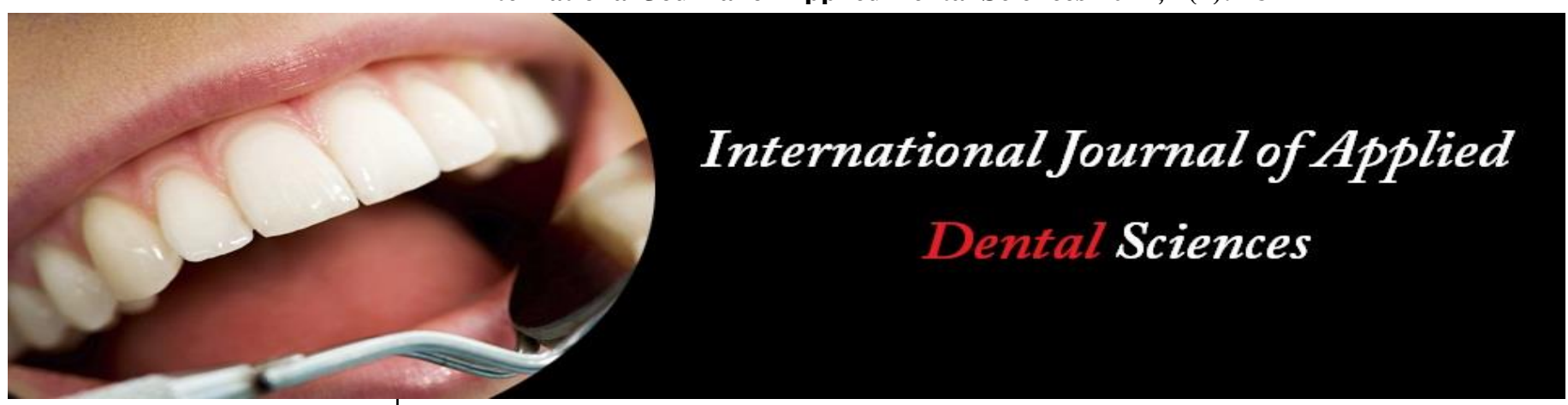

ISSN Print: 2394-7489

ISSN Online: 2394-7497

IJADS 2021; 7(2): 18-21

(C) 2021 IJADS

www.oraljournal.com

Received: 13-01-2021

Accepted: 19-02-2021

Poorna Chaudhary

$3^{\text {rd }}$ Year Post Graduate Student,

Department of Orthodontics and

Dentofacial Orthopaedics,

Subharti Dental College, Swami

Vivekanand Subharti

University, Meerut,

Uttar Pradesh, India

\section{Amit Khera}

Associate Professor, Department of Orthodontics and Dentofacial Orthopaedics, Subharti Dental

College, Swami Vivekanand

Subharti University, Meerut,

Uttar Pradesh, India

\section{Shalu Jain}

Associate Professor, Department of Orthodontics and Dentofacial Orthopaedics, Subharti Dental College, Swami Vivekanand

Subharti University, Meerut,

Uttar Pradesh, India

\section{Pradeep Raghav}

Professor and Head, Department of Orthodontics and Dentofacial Orthopaedics, Subharti Dental College, Swami Vivekanand Subharti University, Meerut, Uttar Pradesh, India
Corresponding Author: Poorna Chaudhary $3^{\text {rd }}$ Year Post Graduate Student, Department of Orthodontics and Dentofacial Orthopaedics, Subharti Dental College, Swami Vivekanand Subharti

University, Meerut,

Uttar Pradesh, India

\section{Role of occlusal splints in temporomandibular joint disorder}

\section{Poorna Chaudhary, Amit Khera, Shalu Jain and Pradeep Raghav}

DOI: $\underline{\text { https://doi.org/10.22271/oral.2021.v7.i2a.1184 }}$

\section{Abstract}

The management of TMD is difficult and controversial. Treatment options for TMD include patient education, behavior therapy, physiotherapy, occlusal splint therapy, drug therapy, occlusal adjustments, surgical intervention, and combined treatment. The purpose of this article is to review the different type of occlusal splints and their role in managing TMDs.

Keywords: occlusal splints, temporomandibular joint disorders, occlusal adjustments, behaviour therapy

\section{Introduction}

Occlusal is the foundation of dentistry. Sound and stable occlusal relationships are basic to successful masticatory function.

Over the years, functional disturbances of the masticatory system around TMJ have been identified by different terms. Temporomandibular joint disorders (TMDs) is the most frequent and latest term used to describe this group of symptoms around the TMJ ${ }^{[1,2]}$.

The successful management of TMDs depends on identifying and controlling contributing factors like occlusal factors, trauma, emotional stress, and parafunctional habits.

\section{Occlusal Splints}

Occlusal splint therapy has been used for many years for the diagnosis and treatment of various disorders of the masticatory systems ${ }^{[3]}$. It is defined as "the art and science of establishing neuromuscular harmony in the masticatory system by creating a mechanical disadvantage for parafunctional forces with the removable appliances" ${ }^{[4]}$. It is a diagnostic, relaxing, repositioning, and reversible device.

\section{Principle of Occlusal Splint}

Most occlusal splints have one primary function which is to alter an occlusion, so it does not interfere with complete seating of the condyles in centric relation ${ }^{[5]}$.

\section{Theories of Occlusal Splint}

1. Occlusal disengagement theory

2. Restored vertical dimension theory

3. Maxillomandibular alignment theory

4. TMJ reposition theory

5. Cognitive awareness theory

\section{Functions of Occlusal Splint}

- Stabilization of week teeth.

- Distribution of occlusal forces

- Reduction of wear

- Stabilization of unopposed teeth. 


\section{Limitation of Occlusal Splint}

It cannot cause effects that violate mechanical laws. Hence it does not unload the condyles. The popular claim that a posterior occlusal splint can distract condyles violates facts of anatomy, laws of physics, and clinical data.

\section{Classification of Occlusal Splint}

A. According to Dawson ${ }^{[5]}$

a. Permissive splints or muscle deprogrammer

- They are designed to unlock condyle to slide freely into centric relation. Hence occlusion is unlocked by removing deflecting tooth inclines.

- They have a smooth surface that can face either the upper or lower arch if the mandible can freely get positioned into centric relation.

\section{b. Directive splint or non-permissive splint}

- They are designed to direct condyle to a predetermined position.

- The main purpose of this appliance is to position or align condyle-disc assemblies.

- Hence, they should be used in intracapsular TMDs.

\section{c. Pseudo permissive splints}

\section{i. Soft splints}

- They are designed to achieve even and simultaneous contact with opposing teeth.

- They are usually adapted to the upper arch.

- The resilient material is used for their fabrication.

- As it is quick to fabricate hence it can be used as an emergency treatment for acute TMD patients.

\section{ii. Hydrostatic splint}

- They are designed to balance the biting pressure by employing water.

- A sequence of reorganization spreads through the stomatognathic system when the hydrostatic cell is inserted between the arches.

- By the distribution of fluid within the cell, all occlusal disharmonies are compensated automatically.

B. According to Okeson [6]

a. Muscle relaxation appliance or stabilization appliance

- Other names for this appliance are superior repositioning splint, the Tanner appliance, the Michigan splint, the Fox appliance, or the centric relation appliance.

- This splint provides an optimal occlusal relationship in the masticatory system.

- In optimal position- condyles are musculoskeletally stable and simultaneously teeth are contacting with canine disocclusion of posterior teeth during eccentric movement.

b. Anterior repositioning appliance or Orthopaedic repositioning appliance

- This splint affects the physiological topographical relationship of the disc condyle complex.

- It induces a therapeutic mandibular position which is forward to the maximum intercuspation position of the patient.

- Hence, it places the mandible and TMJ into an anterior position which reduces the TMJ click that occurs on opening and closing of the jaw.

\section{c. Anterior bite plane}

- An anterior bite plane is a hard-acrylic appliance worn over the maxillary teeth.

- It provides contact with only the mandibular anterior teeth.

- It eliminates the influence of posterior teeth in the function or dysfunction of the masticatory system by disengaging them.

\section{d. Posterior bite plane}

- The posterior bite plane is usually fabricated for the mandibular teeth.

- It consists of areas of hard acrylic which are located over the posterior teeth and connected by a cast metal lingual bar.

- The main goals of the posterior bite plane are to achieve major alterations in the vertical dimension and mandibular repositioning

\section{e. Pivoting appliance}

- The pivot splint is also known as a distraction splint.

- The pivot splint was introduced by Krough-Poulsen.

- It is a hard-acrylic appliance that covers one arch and usually provides a single posterior contact in each quadrant.

- This contact is usually established as far posteriorly as possible.

- The proposed effect is that the condyles are pulled downward upon clenching on the pivot, thereby relieving traumatic load and giving the disc freedom to reassume a normal position.

\section{Others}

a. Bitewing according to Shore

- This splint has a design similar to the stabilization splint but does not

extent onto the facial or buccal surfaces of the teeth and covers the entire palatal area.

- It may be preferred by some patients who need to use the splint during the daytime, for esthetic reasons, because it can be made less visible

\section{b. Cap splint}

- A cap splint can be described as an intermediary between a splint and a bridge.

- It is useful for temporary reconstruction before a final decision about design, vertical surface in hard acrylic

c. NTI (Nociceptive Trigeminal Inhibition) Tension Suppression System

- This was given by Dr. James Boyd.

- The direct stimulation of the periodontal ligament of the lower incisors activates a feedback loop, which significantly limits the contraction intensity of the closing muscles

\section{d. Splint for protection of oral tissue}

- The most common reason for making a splint is to protect the teeth from excessive abrasion in bruxers.

- Several variations of splints are designed to protect cheeks and tongue in patients with oral parafunctional 
(such as cheek biting or tongue thrust).

\section{e. Combination splint}

- Missing teeth can easily be replaced by adding artificial teeth to the

splint.

- A Shore splint can function as a temporary partial denture by adding artificial teeth.

- There are numerous combinations of splint and orthodontic appliances. A removable bionator appliance can act both as an orthodontic and as a repositioning appliance.

- An "invisible retainer" can simultaneously act as a soft acrylic splint.

\section{Role of occlusal splint in TMDS Myofacial pain}

Over five decades treatment by occlusal splints have been accepted, although the mechanism of action of oral splints is not clear. The high clinical success rates achieved with splints alone, whether inserted into the maxillary or mandibular arches or combined with other therapies are overwhelming [7${ }^{11]}$. Its been observed that when we deal with musculoskeletal pain of unknown origin, trying to cure the condition is simply an absurd exercise. As a dentist, we can simply try to improve patient's perception of his/her condition and quality of life. All the previous literature shows that the quality of life improved significantly by using splint therapy. ${ }^{12}$ Latest study performed by using a low-level laser (Nd: YAG) therapy and occlusal splints was also found effective in decreasing myofascial pain ${ }^{[13]}$.

\section{Disc displacement disorders}

\section{Treated with stabilization splint}

Several uncontrolled studies have reported the effectiveness of Stabilizing splints in decreasing pain and joint noises, and in improving the range of mandibular motion ${ }^{[14,15]}$.

However, when studies with control groups were compared noticeable differences in pain, joint sounds, and a maximal opening were observed with the use of stabilizing splint, but no significant difference could be found between groups. All the reports supported that the symptoms associated with disc displacement with reduction (DD) or disc displacement without reduction(DDWR) improve over time without treatment ${ }^{[16,17]}$. In contrast, there is a study in which even without treatment, pain decreased in $36 \%$ of the patients diagnosed with DDWR after one year ${ }^{[16]}$ Whereas symptoms worsened in the treatment group as compared with the control group. Similarly, in another study significant increase in mouth opening and decrease in pain after one year was reported in $41.9 \%$ of the patients with DDWR who refused any treatment, although joint noises remained unchanged ${ }^{[17]}$. Hence, considering these data ability to stabilize splints to recapture the articular disc seems doubtful. But the clinical efficacy in the treatment of DD cannot be ignored.

\section{Treated with anterior repositioning splint}

The review of previous literature showed improvement in symptoms like pain and mouth opening in most of the DD treatment, but data did not report the position of the disc by imaging techniques. Hence, the validity of these results is still questionable as these studies failed to observe many of the rules of clinical trials that are now considered critical ${ }^{[18]}$. So these studies should better be qualified only as case series because of the absence of a control group, several studies [17, $19,20]$. In a few of the studies even if the control group was taken but as blinding was not done hence results are subject to bias ${ }^{[17,21]}$. Furthermore, since patients were not randomized into treatment groups whether these results were mainly due to splint treatment or to group allocation bias cannot be determined ${ }^{[21]}$. Study showed that $40 \%$ of the patients who had only counseling for DD were symptom-free even after 815 years, which remained unchanged in $50 \%$ and was aggravated in $7 \%$ of the patients. A three-year follow-up of 70 patients with DDR, symptoms relapsed after splint treatment wherein reciprocal clicking remained unchanged in $71 \%$ of the patients and disappeared in $29 \%{ }^{[17]}$.

In a study conducted by Greene and Laskin ${ }^{[22]}$, where they treated their patients with painful clicking joints with conservative approaches. In results it was reported that in $30 \%$ the joint noises had disappeared, 33\% reported improvement, and $36 \%$ reported no change. When De Lowe et al. ${ }^{[23]}$ compared the findings in 99 patients with clinical signs of DD before and 30 years after non-surgical and nonrepositioning treatment, they found that the degree of mouthopening remained stable (and acceptable) in patients with DDR, but increased significantly in the majority of patients with DDWR. The prevalence of joint clicking remained unchanged in both groups. Hence, the generally favorable prognosis observed during the natural course of DD speaks against the use of any splint therapy.

\section{Conclusion}

The occlusal splint is a means of reinforcing the auto management of the patient as it offers them the opportunity to control dysfunctions by themselves. Though splint designs and materials used have varied considerably during the past 150 years, effective treatment can be attained with an interocclusal appliance. A major benefit is that if splint therapy is unsuccessful then the splint can be discarded, with no irreversible changes to the patient's natural dentition. If splint therapy is successful, the patient can retain the splint to use on an as-needed basis. If the symptoms get reduced it will provide additional diagnostic information. The clinician also needs to consider that $40 \%$ of patients suffering from TMD demonstrate a favorable response to therapy from a placebo effect. As with any treatment, a good patient-dentist relationship, and concomitant with patent education, can alloy patient feelings and anxieties. It can contribute to a positive and favorable response to intra-oral occlusal splint therapy.

\section{References}

1. Bell WE. Clinical management of temporomandibular disorders. 1st ed. Chicago: Yearbook Medical 1982;12871.

2. Dworkin SF. LeResche: Research diagnostic criteria for temporomandibular disorders: review, criteria, examination, and specification. J Craniomandib Disord Facial Oral Pain 1992, 301-55

3. Kreiner M, Betancor E, Clark GT. Occlusal stabilization appliance. Evidence of their efficacy. J Am Dent Assoc 2001;132(6):770-7.

4. Dylina TJ. A common-sense approach to splint therapy. J Prosth Dent 2001;86(5):539-45.

5. Dawson. Evaluation, diagnosis, and treatment of occlusal problems. 1st ed. Mosby Elsevier 2007;32:379

6. Okeson JP. Management of temporomandibular disorders and occlusion. 6th ed. Philadelphia: Mosby Elsevier 2008, 130. 
7. Carraro JJ, Caffesse RG. Effect of occlusal splints on TMJ symptomatology. J Prosthet Dent 1978;40(5):563-6.

8. Dahlström L, Carlsson GE, Carlsson SG. Comparison of effects of electromyographic biofeedback and occlusal splint therapy on mandibular dysfunction. Eur J Oral Sci 1982;90(2):151-6.

9. Suvinen T, Reade P. Prognostic features of value in the management of temporomandibular joint paindysfunction syndrome by occlusal splint therapy. J Prosthet Dent 1989;61(3):355-61.

10. Tsuga K, Akagawa Y, Sakaguchi R, Tsuru H. A shortterm evaluation of the effectiveness of stabilization-type occlusal splint therapy for specific symptoms of temporomandibular joint dysfunction syndrome. J Prosthet Dent 1989;61(5):610-13.

11. Quayle AA, Gray RJ, Metcalfe RJ, Guthriet E, Wastell D. Soft occlusal splint therapy in the treatment of migraine and other headaches. J Dent 1990;18(3):123-9.

12. Feine JS, Lavigne GJ, Lund JP. Assessment of treatment efficacy for chronic orofacial pain. Int Congr Ser 1995;1079(1):257.

13. Demirkol N, Sari F, Bulbul M, Demirkol M, Simsek I, Usumez A. Effectiveness of occlusal splints and lowlevel laser therapy on myofascial pain. Lasers Med Sci 2015;30(3):1007-12.

14. Chen CW, Boulton IL, Gage JP. Effects of splint therapy in TMI dysfunction: A study using magnetic resonance imaging. Aust Dent J 1995;40(2):71-8.

15. Choi BH, Yoo IH, Lee WY. Comparison of magnetic resonance imaging before and after nonsurgical treatment of closed lock. Oral Surg Oral Med Oral Pathol 1994;78(3):301-05.

16. Lundh H, Westesson PL, Eriksson L, Brooks SL. Temporomandibular joint disk displacement without reduction. Treatment with flat occlusal splint versus no treatment. Oral Surg Oral Med Oral Pathol 1992;73(6):655-58.

17. Sato S, Kawamura H, Motegi K. Management of nonreducing temporomandibular joint disk displacement. Evaluation of three treatments. Oral Surg Oral Med Oral Pathol Oral Radiol Endod 1995;80(4):384-8

18. Spilker B. Guide to clinical trials. 2nd ed. New York: Raven Press 1991, 12-16

19. Simmons HC, Gibbs SI. Recapture of temporomandibular joint disks using anterior repositioning appliances: An MRI study. J Cranio Pract 1995;13(4):227-37.

20. DeRouen T. Statistical and methodological issues in temporomandibular disorder research: Temporomandibular Disorders and Related Pain Conditions. Int Assoc Study Pain 1995;13(1):459-65.

21. Tallents RH, Katzberg RW, Macher DI, Roberts CA. Use of protrusive splint therapy in anterior disk displacement of the temporomandibular joint: a 1- to 3-year follow-up. J Prosthet Dent 1990;63(3):336-41.

22. Greene CS, Laskin DM. The long-term status of TMJ clicking in patients with myofascial pain and dysfunction. J Am Dent Assoc 1988;117(3):461-65.

23. Lowe AA. Dental appliances for the treatment of snoring and obstructive sleep apnea. In: Principles and practice of sleep medicine. 2nd ed. Philadelphia: Saunders 1994;57(1)722- 35 . 